\title{
Manifestações textuais (insubmissas) travesti
}

\author{
Sara Wagner York/Sara Wagner Pimenta Gonçalves Jr ${ }^{1}$ (D) 0000-0002- \\ $4397-891 \mathrm{X}$ \\ Megg Rayara Gomes Oliveira ${ }^{2}$ (D) 0000-0001-9203-9989 \\ Bruna Benevides ${ }^{3}$ \\ 'Universidades Estácio de Sá, Rio de Janeiro, RJ, Brasil. 20261-063 \\ 2Universidade Federal do Paraná, Programa de Pós-Graduação em Educação, \\ Curitiba, PR, Brasil.81020-430 - ppge.ufpr@gmail.com \\ ${ }^{3}$ Marinha do Brasil, Niterói, RJ, Brasil. 24049-900 - bnrj.secom@marinha.mil.br
}

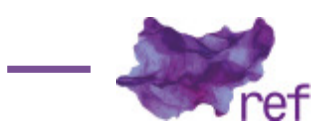

\begin{abstract}
Resumo: A cisgeneridade-binária, heterossexual e compulsória como regime de governamentalidade (Michel FOUCAULT, 1979) determinou, por muito tempo, pressupostos que abarcam marcas profundas com seus estabelecidos normativos. As normas, marcadas pelo regime, acorrentaram as multiplicidades sexuais e de gênero fora daquilo que compreendia o social no Brasil e em boa parte do mundo. $A$ marca repulsiva e marginalizada impressa pelos pressupostos da cis-hetero-governamentalidade de identidades de gênero e sexo no Brasil tem sua emergência a partir dos estudos que nomeavam como substantivo masculino as travestis, os primeiros corpos ciborgues (Donna HARAWAY, 1994) do/no Brasil. Além disso, tal dinâmica marcava corpos travestis em uma condição de não lugar. Muitos estudos abriram trincheira por vales colonizados na tentativa de descrever as subjetividades travestis, além dos essencialismos de gênero (Paul B. PRECIADO, 2017). Este manifesto, aos moldes de outros, busca apresentar, a partir de um pensamento travesti, caminhos atravessados pelo transfeminismo e transativismo, para um futuro travesti, marcado pela luta, afeto e pela presença destas vidas e práticas (transformadoras) em todos os (anti)estratos sociais que operam com o poder da negatividade (Jack HALBERSTAN, 2012). Palavras-chave: manifesto; travesti; transancestralidade; movimentos sociais.
\end{abstract}

Travesti Textual (insubmiss) Manifestations

Abstract: The binary, heterosexual and compulsory cisgenerity as a regime of governance (FOUCAULT, 1979) determined for a long time, assumptions of deep marks in the established norms. The norms, marked by the regime, chained the sexual and gender multiplicities outside of what was understood by society in Brazil and in much of the world. The repulsive and marginalized mark printed by the assumptions of cis-hetero-governamentality of gender and sex identities in Brazil has its emergence from the studies that named the first cyborg bodies (HARAWAY, 1994) in Brazil as male nouns. Moreover, such dynamic marked, travestis bodies, in a non-place condition. Many studies have trenched through colonized valleys in an attempt to describe travestis subjectivities, in addition to gender essentialisms (PRECIADO, 2017). This manifesto, along the lines of others, seeks to present from a travetis thought, paths crossed by transfeminism and transativism, to a travesti future, marked by struggle, affection and the presence of these lives and practices (transformative) in all (anti) social strata that operate with the power of negativity (HALBERSTAN, 2012).

Keywords: Manifest; Travesti; Transancestrality; Social movements.

\section{Manifestaciones textuales (insumisas) travesti}

Resumen: La cisgeneridad binaria, heterosexual y obligatoria como régimen de gobierno (FOUCAULT, 1979) determinó durante mucho tiempo, supuestos de marcas profundas en las normas establecidas. Las normas, marcadas por el régimen, encadenaron las multiplicidades sexuales y de género fuera de lo que entendía la sociedad en el Brasil y en gran parte del mundo. La marca repulsiva y marginada impresa por los supuestos de cis-hetero-gobernabilidad de las identidades de género y sexo en Brasil tiene su origen en los estudios que nombraron como sustantivos masculinos a los primeros cuerpos cibernéticos (HARAWAY, 1994) en Brasil. Además, tales cuerpos dinámicos marcados, de travestis, en una condición de no lugar. Muchos estudios han recorrido los valles colonizados en un intento de 
describir las subjetividades de las travestis, además de los esencialismos de género (PRECIADO, 2017). Este manifiesto, en la línea de otros, busca presentar desde un pensamiento travesti, caminos cruzados por el transfeminismo y el transativismo, a un futuro travesti, marcado por la lucha, el afecto y la presencia de estas vidas y prácticas (transformadoras) en todos los estratos sociales (anti) que operan con el poder de la negatividad (HALBERSTAN, 2012).

Palabras clave: manifiesto; travesti; transancestralidad; movimientos sociales.

\section{Manifesto}

Quando nos aproximamos da própria ideia de um manifesto encontramos algumas definições aproximativas como, por exemplo: 1) ser uma declaração trazida a público; 2) ser uma declaração solene de um partido, um grupo religioso, ou, ainda, de artistas; 3) possuir relações de bens para efeitos fiscais; 4) documento que não pode ser contestado ou oculto; 5) adjetivo para aquilo que se revela por sua evidência. Nestas definições que podemos localizar de forma mais ou menos elaboradas, em diversos dicionários encontramos elementos políticos, religiosos e artísticos, mas, também, elementos jurídicos, legais e burocráticos.

Desta forma, quando nos aproximamos da composição de um manifesto travesti devemos remontar, também, à linha dura e à linha de fuga de um manifesto. A linha dura trata do manifesto ser um elemento do poder do soberano (FOUCAULT, 1988).' O soberano manifesta a sua vontade - intenções e leis - para os seus súditos. Não obstante, ainda hoje, a definição de manifesto tem no seu lastro uma questão burocrática e prescritiva. A linha de fuga é a própria usurpação da autoridade soberana. Neste momento poderíamos pensar numa prática que definiu o próprio pensamento queer. Trata-se da subversão dos métodos, da reapropriação dos termos, do roubo criativo de ideias e da extrema antropofagia: um pensamento Travesti.

A respeito da palavra travesti, há uma potente significação, por vezes torpe do verbo, travestir. Seja "travestir" na tentativa posta que em dado momento vincula à sujeira, à doença, a marginal, à maleficência disfarçada, falseada, não genuína. Para nós, por sua vez, a palavra se vincula à luta, à resistência, à dignidade e a uma potencialidade política e contestatória. Uma palavra feminina, um substantivo feminino e nunca um verbo que sujeita e infere. Corriqueiramente, e de forma equivocada, pessoas cisgêneras utilizam a palavra travesti enquanto verbo com desinência de tempo passado, para atribuições de cunho pejorativo, como na frase, "o político, fulano de tal, estava travestido de aliado". Travestido, judiado, denegrido e tantas outras formas que a língua adere à norma ao passo que pune. Quem determina os limites possíveis de se existir enquanto travesti e ter uma experiência de vida que surge impregnada de estigmas e tabus, violência, invisibilidade e negação de espaços?

É desta linha de fuga na palavra do soberano que nos aproximamos. Assim, lembramos que o manifesto, enquanto um gênero literário, traz a sua potência neste aspecto. Alinhamo-nos ao manifesto em produção textual múltipla, pois propõe outras relações éticas, estéticas e de afetos. Esta produção múltipla do manifesto é marcada por uma posição política dentro de uma determinada conjectura cultural e política, e incide com certa urgência. Esta urgência do manifesto nos faz abarcar a atualidade na sua forma mais convulsa, contemporânea, plena em agora.

A celeridade das ações necessárias nos evoca o presente e o cotidiano, mas também uma perspectiva para abertura de futuros possíveis. Neste sentido, o manifesto é uma escrita que intensifica o agora. Ele é feito para que haja possibilidade de mudanças e tensionamentos futuros. A trilogia queer dos manifestos talvez pudesse ser nomeada com: 1) O manifesto Ciborgue, de Donna Haraway (1994); 2) Manifesto contrassexual, de Paul B. Preciado (2017); e 3) Manifesto Gaga, de Jack Halberstam (2012). É evidente que em cada um destes manifestos há suas especificidades e o seu contexto de produção, porém, em todos eles há um programa e uma tentativa de quebrar determinadas barreiras político-epistêmicas, como assim também o é o próprio Manifesto.

Ao contrário do imaginário do senso comum, ser uma travesti é o reconhecimento de um outro corpo possível, legítimo, além daquele normatizado. É a constituição de uma identidade real (quando apresenta materialmente seu corpo), social (quando transita entre os espaços) e política (quando reivindica direitos - de fato e de direito). Essa mesma identidade social, que é produtora de cultura, rompe com os signos binários estáticos e expressa-se como pertencente ao gênero feminino. A disruptura às normas sociais, ao longo da história, colocava as travestis às margens sociais, expondo ou naturalizando práticas de violência (estrutural, simbólica, patrimonial, psicológicas e físicas), além da exclusão social comumente praticada por parte da população contra nós.

${ }^{1}$ O direito é formulado na vida e na morte; de causar a morte ou de deixar viver. O Poder Soberano, antes de tudo, é o direito de apreensão do tempo, dos corpos e, finalmente, da vida. O ponto máximo desse poder é o privilégio de se apoderar da vida para depois, caso assim o desejasse, suprimi-la (FOUCAULT, 1988). 
O direito à autodeterminação delibera a todos os corpos (cis/trans) a possibilidade da autonomia sobre a escolha em retificar nome e gênero e, com isso, uma vez mais experienciam a adequação à norma como única forma de inserção cível e acesso às políticas públicas. Nos adequamos para sobreviver. Assim, aquelas que decidiram não emergir para uma vida "fora do armário" seguem em sua travestilidade, transexualidade ou transvestigeneridade, gozando de direitos ou confortos que deveriam operar sobre todas.

Neste momento, não se trata de uma narrativa solta, mas de enfatizar alguns elementos do próprio exercício de escuta da "voz" travesti. Escutas atentas e outrora feitas por outros vieses que construiriam um arquivo ou banco de memórias para desenho de uma epistemologia e, neste caso, uma trans-epistemologia. A consequência lógica apresentada é que, se existem dispositivos ${ }^{2}$ para a não escuta destas histórias, assim estamos diante de um trans-epistemicídio. Via de regra, as incursões etnográficas feitas por pesquisadoras e pesquisadores brasileiras e brasileiros destacam a presença de travestis e mulheres transexuais em "bairros de periferia, boates, praças, pensões e territórios de prostituição" (Marília dos Santos AMARAL; Talita Caetano SILVA, Karla de Oliveira CRUZ; Maria Juracy Filgueiras TONELI, 2014, p. 302), raramente no campo do conhecimento, especialmente o acadêmico.

O preconceito que surge como principal obstáculo de travestis e transexuais até a graduação ganha uma outra forma nos programas de mestrado e doutorado. Nesse ambiente, as poucas pesquisadoras trans sofrem questionamentos velados quanto à sua isenção, especialmente quando estudam o universo LGBT (Paula MARTINI; Gabriel SABÓIA, 2018).

No caso da explicitação do corpo travesti e suas histórias, podemos pensar em estratégias que desestabilizam a voz travesti antes mesmo de ela falar ou emitir qualquer ruído. Trata-se de palavras como: vitimismo, coitadismo e denuncismo. É possível que encontremos palavras correlatas, mas, são estas três, que, na atualidade, criam um muro na escuta da voz travesti, sendo uma das faces de operação da transfobia.

Estamos diante da interpelação de Gloria Anzaldúa (2005) e sua auto-história teórica. É possível observar os limites e borrões entre a descrição de histórias de vidas enquanto elaboração de um quadro em movimento que a todo tempo pergunta quem é travesti, quem é trans e o que seria drag? O que as difere? Quem pode dizer: tire a barba para ser mulher? Quem pode determinar a quantidade de maquiagem sobre a pele que um corpo travesti apresenta? Quem pode dizer a alguém que ela não é travesti, senão ela mesma? Quem pode autoidentificar alguém? Mas é fato que algumas de nós, por seguirem exotificadas (Grada KILOMBA, 2019), seremos arremessadas aos ritos do super-humano ou sub-humano, qualidade sentida por travestis ao serem retratadas como divas dos palcos ou como abjetas e SIDAdãs (Larissa PELÚCIO, 2009) de segunda classe em um mundo de diverCISdade.

Por muitas vezes, cruzando fronteiras de sentimentos intensos e múltiplos meandros, a travesti que ganha o concurso de Miss é a mesma que está desempregada e é obrigada a recorrer (muitas vezes) à prostituição e à noite para garantir sua subsistência, e não há nada errado nisso, desde que essa não seja a única opção. O posicionamento diante de complexidades tão fronteirísticas erroneamente ganham conotação pejorativa, principalmente, numa compreensão cis-fálica-sexista (Maria Luiza SUSSEKIND; Sara Wagner YORK; Lorena CARMO, 2020). Esta compreensão cis-fálica-sexista (SUSSEKIND, YORK, CARMO, 2020), que engendra regimes de verdade (FOUCAULT, 2010, p. 67), é a própria produção destes epistemicídios já salientados em escritos folclóricos e com recortes precisos nos elaborados de muitos narradores e sua visão de diverClSdade.

Estas noções difusas de vitimismo, coitadismo e denuncismo que surgem diante de qualquer storytelling desconhecem a própria vivência travesti em sua radicalidade. Os processos de violência e vulnerabilização experienciados pela população travesti são tão apavorantes, que apenas os dados gerais como mortes ${ }^{3}$ e torturas ganham um pouco de atenção por parte da mídia e do grande público - em um grande circo de horrores que denuncia a estrutura sistêmica de exclusão e exotificação de seus corpos mutilados, muitas vezes desnudos para lembrar que aquele corpo não deveria existir ou ser aceito como humano.

A veiculação exaustiva, nas redes sociais, do corpo trucidado da travesti negra Verônica Bolina por meio de imagens que habitam o campo do abjeto levanta questionamentos sobre esse mecanismo de denúncia (Rosane BORGES, 2015). A morte ritualizada, como aconteceu com Dandara, em Fortaleza, em 2017, ganha contornos de espetacularização. "Não basta um tiro fatal, ou uma facada precisa ou um atropelamento definitivo. Os corpos são mutilados por dezenas de facadas, por inúmeros tiros. Os corpos são desmembrados pelo peso do carro que o atropela várias vezes" (Berenice BENTO, 2014). Esses rituais revelam "um desejo social de eliminação da existência trans com a conivência do Estado brasileiro" (BENTO, 2014).

\footnotetext{
${ }^{2}$ Todos os Dispositivos são Dispositivos de Poder e procuram atribuir ao corpo alguma utilidade e permitem o controle minucioso de suas ações e asseguram a sujeição constante de suas forças e lhe impõem uma relação de docilidadeutilidade (FOUCAULT, 1979).

${ }_{3}^{3}$ Para saber mais, consultar Relatório Completo de Assassinatos de Travestis e Transexuais da Antra. Disponível em https://antrabrasil.org/assassinatos/.
} 
Enquanto travestis, dormimos crianças e (raramente) adolescentes (sendo que a adultização de nossos corpos, muitas vezes, nos impede de acessar a adolescência) e em um passe de mágica, ao dizermos algo que relacione o desejo físico ao corpo, até então lido como homoerótico, em questão de segundos, nos tornamos adultas maliciosas. Pervertidas.

Trata-se de explicar, com este conceito, tanto uma história que antecede o corpo (trans)generificado(r) da travesti, quanto o exercício do abandono de um "si mesmo" por longos períodos de tempo, dado o exercício constante do esforço resistente frente à transfobia instaurada por um Estado aniquilador. ${ }^{4}$ Este segundo elemento é sentido de forma recorrente por pessoas de situação de rua, usuárias de drogas e travestis. É a dor do abandono por outros e, por algum momento, por si.

Diante de violências, em um primeiro momento somos levadas a crer que nestes casos seria necessária uma denúncia. Mas para a população travesti, onde falar não é permitido e reinvidicar um direito lhe é negado, a denúncia não é uma opção capaz de ser ouvida ou levada a sério por parte de muitos agentes que ocupam instâncias públicas de atendimento. Se faz recorrente uma leitura subsequente que termina por ser nomeada de coitadismo e seu praticante o vitimista. Não se trata apenas de apontar o problema (denúncia), mas abri-lo como um chamado de ajuda e construção de uma resposta, onde quem critica não apresenta resposta, mas exige da própria vítima uma solução-resposta. ${ }^{5}$

Exigir da vítima uma resposta seria uma forma de colocá-la em situação de revitimização, que compreende negligência, imperícia ou omissão, afastando a possibilidade de que ela se sinta capaz de seguir em frente na reivindicação do que parece algo simples para um olhar cisgênero desatento. Esquecendo que o alvo que ela carrega, após uma denúncia, se torna ainda maior, pois esta ousou se apropriar de uma ferramenta que não foi pensada para ela. E que, por isto, não seria um direito seu usar da denúncia para qualquer reparação pelo mal que lhe acometera, visto que o processo de exigir respostas dela enquanto vítima a coloca como culpada por aquilo que lhe aconteceu. A pergunta que é feita à vítima ainda é "o que você fez para que isso acontecesse?".

O fator revitimizador acontece quando pessoas em situação de vulnerabilização precisam responder a questões que são agudas ao tratarmos de agressão, de mesmo modo a constante nuvem da violência simbólica naturalizada contra a travesti ao negligenciarem seu gênero ou o pronome correto no tratamento/atendimento. Perguntas de caráter agressor (feitas por instâncias estatais ou não) e que gerem danos ou sofrimento à vítima em função de negligência, afirmação, ou imperícia cometido pelo agente do estado, naquele momento que gere a potencialização da dor, consequência negativa ou sofrimento para a vítima. ${ }^{6}$

Muitas denúncias envolvendo pessoas trans terminam sendo desencorajadas e sistematicamente não investigadas, inconclusivas ou ignoradas (ANTRA, 2019). São corriqueiras tais situações na vida das travestis que têm suas existências negadas enquanto cidadãs. E quando falamos daquelas que estão expostas nas ruas, em sua maioria negras, cujo destino ainda é a prostituição, cogitar a efetivação de uma denúncia seria uma escolha entre lidar com descaso no atendimento, na reivindicação do direito, ou ainda enfrentar o risco de se colocar novamente em situação de hiperexposição, quando ainda vemos agentes do estado sendo responsáveis por diversas violências e violações.

Como ela poderia denunciar ao estado o seu próprio agente, e exigir proteção, ou que o mesmo estado cuide de sua segurança? Como ela poderia denunciar um assalto ou calote de um possível cliente, se no momento do registro de ocorrência vale mais a palavra do "cidadão de bem" que tem voz, e que se negou a pagar seu programa, e a acusa de tê-lo tentado assaltar invertendo a situação, reforçando estigmas e se livrando assim de ter exposta sua sexualidade maculada pela descoberta do prazer em sair com uma travesti? Como ela poderia denunciar um agente do estado ou um cidadão de bem, e no momento seguinte voltar às calçadas, exposta àqueles que jamais deveriam ser apontados por alguém como ela?

Perceba que em um único dia a mesma travesti desejada e olhada "de cima a baixo" pode ser apontada por pessoas nas ruas como objeto de chacota, tratada com desdém ou acusada de "atrevida ou escandalosa" se for questionadora da suposta autoridade moral de algum opressor. Daniela Andrade, 7 em sua página no Facebook, diz que "um dia travesti aos corpos cisheteros já seria o suficiente para mudar o número de travestis mortas nas estatísticas".

\footnotetext{
${ }^{4}$ Um Estado que dificulta e, em muitas situações, impede que travestis se constituam como sujeitas de direito. Essas situações se materializam quando a anatomia biológica se sobrepõe à identidade de gênero, minando o acesso a direitos essenciais como educação, saúde, segurança, dentre outros, aniquilando, concretamente, a possibilidade de ser vista e reconhecida como pessoa. Assim, "da mesma forma que a sociedade precisa de modelos exemplares, de heróis, os não exemplares, os párias, os seres abjetos também são estruturantes para o modelo de sujeitos que não devem habitar a nação" (BENTO, 2014).

5 Jaqueline Gomes de Jesus, em áudio a partir do grupo on-line "TRANSacadêmicas", no dia 11/03/2019.

${ }^{6}$ Artenira Silva, Professora e Doutora em Psicologia, cuja área de estudo envolve vítimas atendidas pela lei Maria da Penha. Em conversa via WhatsApp a partir do grupo on-line "Políticas TRANS BR".
} 
O que pode ser percebido é a existência de uma legalidade nas ações objetivadas e a transfobia estrutural por parte de uma sociedade, e governo, com características heterocentradas e cisnormatizadas que insistem, desde a década de 1970, com a ajuda do aparato policial, que "pôs em curso um processo de higienização e caça [...] às travestis" (Fernanda Dantas VIEIRA, 2015) na tentativa, pouco produtiva, de eliminar, simbólica e fisicamente, esses desviantes de "sexo-gênero" (VIEIRA, 2015).

\section{Ativismo Corporal}

As experiências de vida de travestis e mulheres transexuais na sociedade brasileira passaram a ser temas de pesquisas acadêmicas com mais frequência a partir da década de 1990. É, no entanto, após os anos 2000 que esses estudos passaram a ter maior visibilidade e despontaram como temática central em pesquisas brasileiras (AMARAL, SILVA, CRUZ, TONELI, 2014) graças ao aumento substancial dos estudos que tematizam gênero e sexualidade.

Os primeiros pesqui(cis)zadores ${ }^{8}$ foram atrevidos ao entrar por esta seara, invadindo os não lugares designados àqueles destinados à existência possível das travestis - onde se constituíam enquanto uma sociedade paralela, se relacionavam, conviviam entre si, (des)construíam seus corpos, (re)construíam suas identidades e sua própria sexualidade, e de quem as procurava.

Não havia muita coisa na esfera social, tampouco na literatura. Alguns textos jornalísticos depreciativos reforçavam estigmas, faltavam registros com recorte humano e sobravam muitos contendo abusos. Os registros policiais e as internações em sanatórios vão subsidiar muitas reflexões a respeito dessa exclusão e reforçar a invisibilidade social.

As histórias de Madame Satã, Cintura Fina, Tomba Homem, Cris Negão, por exemplo, seriam escritas por meio dos registros policiais que operavam como dispositivo de controle social. A maioria experienciava a expulsão (a que Luma Nogueira de Andrade [2012] denomina evasão involuntária) escolar logo no final da infância, e apesar de a maioria ser analfabeta e/ou não letrada, barganhava com os/as pesquisadores/as as informações que ela desejava, usando as tecnologias travestis de (re)existência da esquina, da pista e do asfalto, lugar onde estes/as mesmos/ as pesquisadores não conseguiriam permanecer sozinhos pelo tempo de um programa.

Estes/as primeiros/as pesquisadores/as queriam saber sobre a dinâmica daqueles corpos, e do que eles eram capazes. Como se organizavam, comiam e viviam totalmente fora de qualquer possibilidade de inclusão social. Havia uma moeda de troca ao falarem abertamente de suas vivências, que seriam registradas pelo pouco doado, mas que lhes parecia muito. Esses/as mesmos/ as pesquisadores/as conseguiram cartografar e desenhar as primeiras categorias da existência de um corpo travesti (Dayana Carlin Brunetto dos SANTOS, 2010; Wiliam Siqueira PERES, 2009; Rogério Diniz JUNQUEIRA et al., 2009; AMARAL, SILVA, CRUZ, TONELI, 2014). Em suas pesquisas, a escolha da fotografia capturada e revelada expõe a parcialidade necessária da luz para que a imagem ganhe forma.

Sem estas pesquisas para pensarmos em contrapor a ideia, o recurso que nos é permitido hoje não seria possível, diante desta necessária leitura de e para nossas primeiras compreensões que revisitam estes lugares para resgatar o que foi deixado de lado. De posse de bens materiais e imateriais, a partir da luta das primeiras travestis militantes, aprendendo a resgatar nossa própria história, narrativa e voz para pensarmos em como sobreviver e resistir, aprendemos a ler e escrever para proporcionar a ocupação de espaços anteriormente negados nos bancos escolares e com a possibilidade de diálogo em um governo que abarcava a redemocratização, algumas se tornaram doutoras e pesquisadoras.

Foram as travestis que ajudaram a constituir e estruturar o Movimento Gay, e acabaram ficando de fora das ações políticas desenvolvidas por ele. Vale lembrar que a luta contra a despatologização do "homossexualismo" não trouxe consigo a causa trans. E a construção deste corpo travesti passa por uma disputa no campo epistemológico com narrativas que trazem, além do olhar observador, a representatividade e o pertencimento ao grupo que vinha sendo estudado, apenas sob o olhar cisgênero.

Portanto, a ideia de um corpo travesti ou trans ganha propriedade discursiva a partir do compor ou contrapor exposições anteriormente feitas a respeito delas, sobre elas e, agora, por e com elas. Enquanto estes/as primeiros/as cis-aliados/as marcavam o corpo travesti no masculino, ${ }^{9}$ eles/as evidenciavam a limitação da luz sobre o negativo fotográfico. Para nós, leitoras-críticas,

\footnotetext{
${ }^{7}$ Daniela Andrade é Trans-ativista e utiliza diariamente sua página no Facebook para apresentar seus posicionamentos ético-políticos se tornando, desde então, digital influencer, a partir de seus posicionamentos pouco ortodoxos em maio de 2018.

${ }^{8}$ Aqui é importante trazer que esta composição é tecida por três travestis da educação. Todas atuam de alguma forma nos/dos/com movimentos sociais, mas Bruna Benevides se estabelece na educação a partir de seu ativismo em coordenar e manter o PREPARANEM-Niterói-RJ; Sara Wagner, que atua na educação formal e informal em diferentes níveis com Língua Portuguesa, Pedagogia e Língua Inglesa; e Megg Rayara, professora e doutora que firma sua história na área da Educação. O texto conta com apoio inicial de Rafael Leopoldo.
} 
travestis, a partir destas obras e a partir de outras facilitações, há compreensão de suas limitações na descrição imagética da possibilidade de um existir travesti. Não homem, não mulher. Tudo. Nada. E por ser tudo (e nada) em (com)junto, pertencente ao feminino e ao feminismo, foi preciso ascender um corpo travesti, para que a travesti fosse incorporada à linguagem enquanto substantivo feminino, do mesmo modo que presidenta (José SARNEY, 2010) no Brasil também o foi. Amara Moira Rodovalho (2018) explica por que é tão complexo falar de travestis e pessoas trans:

No que concerne ao debate das identidades de gênero, no entanto, "cis" surge apenas setenta anos após o termo que lhe faz oposição, "trans", este na década de vinte, aquele quase que na virada para o século XXI, e é compreensível a demora. [...] Por obra da violência transfóbica, que tem suas bases bem fincadas no sexismo, aquelas pessoas que ousassem afrontar essa lei seriam mortas ou teriam que voltar de imediato para o armário, dando a impressão falsa de que inexistiam ou de que desexistiram. Foi necessário o surgimento e fortalecimento do movimento feminista e, com ele, a transformação radical dos sentidos que a palavra "mulher" denota para, aos poucos, pessoas criadas para ser homem conseguirem começar a fazer legítima sua reivindicação de existir enquanto mulher e, hoje, pessoas criadas para ser mulher começarem a conseguir fazer com que seja razoável, aceitável a sua reivindicação de existir enquanto homem (o fato de só hoje a ideia de homem trans estar se tornando conhecida, inteligível diz muito sobre o que nossa sociedade reserva às pessoas criadas para ser mulher), que não a predita por seu genital. A verdade é que (estamos) numa sociedade profundamente cissexista (RODOVALHO, 2018. p. 365-366).

Nós, as travestis, antes de nos dizerem quem somos, nunca dissemos que éramos travestis, como também assim acorre com as mulheres, mas assumimos enunciados que cristalizam verdades sobre nossos corpos. Uma sociedade em disputa por nomeação, a partir do status quo, muito chancelada por estes primeiros estudos (BENTO, 2003; SANTOS, 2010; PERES, 2009; JUNQUEIRA et al., 2009; AMARAL, SILVA, CRUZ, TONELI, 2014), que diziam que somos aquilo que eles chamam de travesti, como se fosse uma autoidentificação, mas nunca foi, foi (um) dado e aceito, por nós e por pesquisadores/as/xs que chegaram nesse campo em construção.

Eles/as nos observaram, escutaram, leram, e naquele momento determinaram o que ou quem seríamos, e nós passamos a também nos enxergar daquela forma, desatentas em sua subalternidade (e tudo que ela implica). As pesquisas naquele momento não retornavam aos "objetos implicados", para que qualquer contestação pudesse ser feita. Ainda que retornassem, qual seria a dose de generosidade para o acolhimento de quem se permitiu doar e tão pouco receber?

Temos refletido constantemente sobre quem somos enquanto travestis e sempre nos parece que antes de nos identificarmos como travestis, fomos colocadas neste (não)lugar devido aos processos de exclusão, que muitas vezes se repetem e geram uma confluência de histórias marcadas pela negação.

A travesti que surgia do gueto, das esquinas, das periferias, da negritude e na marginalização de corpos que não constava na literatura médica ou nas escrituras sagradas, hoje abre espaço para aquelas que pouco ou nada sabem sobre os próprios caminhos, e que foram abertos no passado.

Já no século XVI, havia figuras emblemáticas como XICA MANICONGO e JOANE, negras e africanas, denunciadas aos tribunais do Santo Ofício em 1591, em Salvador, por desafiarem as normas de gênero e sairem às ruas em trajes femininos (Megg Rayara Gomes de OLIVEIRA, 2018), reivindicando o direito ao uso do que conhecemos hoje como nome social e o mesmo tratamento que as mulheres cis. Profanas que somos, somos reais e também seres mitológicos. Centauros ou sereias, quase sempre urbanas/os.

Exotificadas, demonizadas, hiperssexualizadas, patologizadas, abusadas, banalizadas e úteis a muitos campos quando convém. Mas sempre donas de si. Donas de nossas não cisgeneridades, donas de nossos corpos a ponto de fazermos o que quisermos com eles. Inclusive, pedir a responsabilização de nossos algozes de vida e de morte.

Se nós, travestis, fazemos o que quisermos com nossos corpos para afirmar quem somos, não duvidem do que somos capazes de fazer para chegar onde queremos. Largaram nossas mãos, apagaram nossa história, retiraram nossos nomes, identidade e direitos. Negaram nossa humanidade. Mesmo assim, nos fizemos aquilo que a sociedade deseja e rejeita, pois reivindicamos uma liberdade, de ser e existir, de desafiar os limites do corpo e da sexualidade que escapa ao controle, denunciando a opressão colocada sobre aqueles que se curvam diante da cisgeneridade compulsória sem contestá-la.

\footnotetext{
9 Larissa Pelúcio, responsável pelo convite para esta composição, durante a generosa "olhada" neste Manifesto, alerta-nos (sobre o uso de artigos masculinos empregados à palavra travesti): "acho que vale lembrar que as próprias travestis assim se referiam a si mesmas. Logo que iniciei meu campo usei o pronome feminino e fui muitas vezes corrigida por travestis. Uma delas me disse: 'você é uma professora e fala errado? Olhe no dicionário, é O travesti'. [...] particularmente, acho injusto que Hélio Silva tenha caído no ostracismo porque escrevia O travesti em 1993".
} 


\section{PERFORMOLECULARIDADE para o tempo}

Os corpos são postos em hierarquias através do enxadrezamento ${ }^{10}$ cênico da vida social que nos dispõe em valores e vão estar submetidos ao conjunto de marcas que imprimem sobre eles ficções políticas que frequentemente pensamos ser naturais. Pensando em Manifesto como obra molecular, contraditória e que atenta aos corpos desviantes, enquandrados ou não como travestis, seria urgente pensar o que pode minar as paredes que sustentam essa ficção. É preciso ser dito que um terceiro gênero"1 ou quarto experiencial seja uma possibilidade humana de conquista e (re)descoberta sobre si mesma.

O reforço ao enquandramento binário de forma compulsória tem trazido corpos transgenerificados (aqueles tornados gendrados e escapadores da forma) para instâncias binárias de reforço ao binário. Travestilizar as formas é prática de luta e desajuste desta forma. Seria o queer travesti? Nós arriscaríamos dizer que sim, pois o corpo travesti (físico, moral ou social) sempre aceitou implantes de (des)adequação, e de desadequadação.

A vergonha e o estigma frequentemente associados não apenas a questões transgêneros, mas com a sexualidade em geral, fazem organizações como as LGBTs, enquanto sociedade histórica, absolutamente vitais em seus mandatos ao adquirir, preservar,e disponibilizar registros [...] (Susan STRIKER, 2008, p. 231).

O Brasil e a população cisgênera possuem um levantamento nacional a partir do IBGE, mas nós queremos conversar com o corpo ciborgue ou a possibilidade dele. Um corpo que se julga completo e se questiona como o corpo cisgênero não há de ser tão distante do corpo travesti (ciborque ou não, uma vez que qualquer adaptação remeteria a uma incompletude). O ciborgue (HARAWAY, 1994) qqui é um corpo/conceito que dialoga com o exótico, o diferente, o artificial, como se fôssemos uma tentativa malsucedida de aproximação com o corpo cisgênero.

Um corpo travesti retratado em educação, previdência, saúde e família. Um corpo ciborgue, em uma lição ciborgue que aprendemos com corpos travestis, ou acaso é sabido que pessoas travestis ainda seguem vistas como sem prioridade no atendimento de saúde no Brasil? Estamos falando de saúde? Sim, estamos falando de pessoas que mal conseguem acessar serviços básicos de saúde, muitas vezes limitadas à população-chave nas (necessárias) políticas de IST, HIV/AIDS. Prioritárias para pesquisa, esquecidas para campanhas focais.

A questão de saúde talvez tenha sido a área que mais trouxe atenção e gerou a possibilidade de entrada e acesso das travestis na atenção básica. Seja por meio dos programas de prevenção as IST, HIV e AIDS, o processo transexualizador ou mesmo pesquisas importantes que trazem um diagnóstico que denuncia a precariedade da saúde travesti causada pelo próprio estado ao negligenciar nossa população, pois ignora a existência de corpos que não estão sendo estudados ou lidos como possíveis.

Criando conhecimento e gerando ferramentas que têm sido usadas pelo movimento de travestis para fazer reivindicações que atravessam a questão da saúde, e que transversalmente geram um debate nas mais diversas áreas sobre quem seriam estas outras possibilidades de existência, que mesmo conhecidas por todas as demais, nunca haviam chegado até aqui, ou podido falar. Seja em debates escolares, na mídia, empresas, ou mesmo entre nós, a fim de enfrentar estigmas e tabus que foram jogados sobre nós.

Se reconhecer enquanto travesti nos faz compreender uma classe na qual busca se pertencer e não o pertencimento, por termos sido jogadas a esta compreensão. Uma compreensão de não lugar, sem nome, laços afetivos, ou humanidade.

O corpo ciborgue aceito e o corpo (ciborgue) travesti e seu silicone industrial são marcadores eficientes da diferença entre o aceito e o não aceito. Algumas travestis poderão chegar mais cedo ou mais tarde à compreensão de si, entretanto, ainda se faz necessário observarmos que ao alinharmos as - ainda poucas - "histórias de sucesso" de algumas vidas travestis, estamos dizendo que não apenas ganhamos a corrida pelo sucesso, mas que conquistamos todo instrumental necessário para ali estarmos.

Em (neo)maquinaria trans (Sara Wagner York Pimenta GONÇALVES Jr, 2019) é apresentado um modo de cooptação travesti para utilização deste sujeit(ad)o nas instâncias neoliberalistas. Uma travesti de sucesso adentra o mundo do trabalho formal sendo lida enquanto travesti? Uma Doutora Travesti adentra programas internacionais sendo travesti? Temos cada vez mais casos que nos dizem que sim, mas é preciso revisar a nossa literatura e verificar que muitas destas pessoas passaram a vida formal experienciando, vivendo e sendo vistas enquanto pessoas cisgêneras (Ana Maria MIRANDA, 2015) e em algum momento, já inseridas, houve a transição - o que muito as

\footnotetext{
${ }^{10}$ Enxadrezamento é a palavra (neologismo) que invoca o jogo de xadrez como forma condensada, estratégias de vida e sobrevida e de luta dos corpos. No jogo de xadrez todas as peças estão prontas para defesa do Rei, mas é a Rainha quem pode realizar a maior defesa e ataque durante a partida.

11 Índia aprovou em 2014 o terceiro gênero, seguindo os passos da Alemanha em 2013.
} 
livra de diversos processos de exclusão, violência e isolamento, já mencionados neste manifesto. Somos corpos marcados pela necropolítica (Achille MBEMBE, 2019). "Corpos matáveis, sem representatividade e sem passado."

Muitas vezes, são nossos tífulos, nossas carreiras, e a forma com que negociamos este acúmulo de elementos a que a maioria das travestis não terá acesso, que nos autorizam a circular por determinados espaços, sem a garantia de sucesso ou segurança. Esses mesmos títulos não nos protegem da travestifobia.

Um suposto respeito é direcionado à nossa não ameaça ao cistema, somado aos nossos títulos e às profissões alcançadas, e não à pessoa da travesti. Logo, somos toleradas e os espaços passam, não a respeitar, mas a ter que lidar com nossa existência travesti. O que seria um "facilitador" em alguns aspectos. Viver ou vivenciar este entreposto, entre o "ser uma mulher não homem", tem sido o quiasma dessa equação que não pede exatidão, mas inclui corpos outros e suas não aceitações às práticas binárias.

Os traçados sobre a Yogyakarta e as travestis, enquanto corpos femininos, ou parte dele, tensionam a compreensão travesti a partir do ponto de vista, o que pode ser dito por e sobre um corpo trans visto de longe e de perto, uma espécie de paralaxe, uma Paralaxe Trans das percepções da cisgeneridade sobre corpos travestis.

Em textos e em nossas próprias vivências subalternizadas (Maria SPIVAK; Martha GILLIAN, 1998), no transcurso do dia a dia, percebemos uma tímida (re)aproximação de algumas pessoas que, ao se aproximarem e terem mais intimidade, se abrem em cuidado e zelo, numa outra forma de experimentar uma convivência travesti. Com o passar do tempo, as várias situações de violência que muitas vezes Ihes alcançam vão sendo forçadas ao afastamento, para sua própria segurança, visto que não conseguiriam seguir um dia sequer sendo travesti.

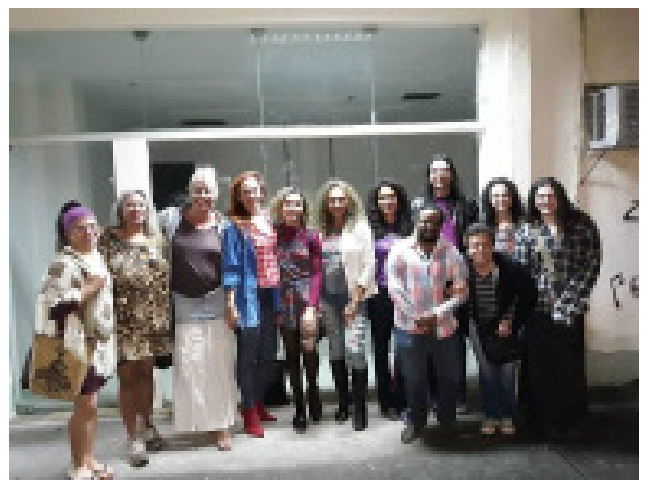

Figura 1: I Seminário Shelida Ayana: Cotas Trans na Graduação e Pós Graduação. A primeira discussão por e entre pares no Brasil, realizada em setembro de 2018 na UFRJ, pelo GE-SER, liderado pelo Prof. Dr. Sérgio Baptista da Silva.

Fonte: Arquivo pessoal de Sara Wagner York/Sara Wagner Pimenta Gonçalves Jr.

\#PraTodoMundoVer: A imagem mostra mulheres e homens trans e travestis ladeadas e em pose para fotografia feita durante evento na calçada de um auditório nas dependecias internas da UFRJ. Na foto (a partir da esquerda): Maiara Fafine, Indianare Shopie, Sara Wagner York/Sara Wagner Pimenta Gonçalves Jr., Giowana Cambrone, Wescla Vasconcelos, Bruna G. Benevides, Jaqueline Gomes de Jesus, Leila Dumaresq, Céu Cavalcanti, Sessiz Canlar, Amiel Vieira e Leonardo Peçanha.

Estas pessoas gozam de diversos privilégios e conquistas que as distanciam de nossa realidade. Presenciar a subalternização trans faz com que não suportem o que passamos. Este fato pode ser visto em muitos textos sobre a não aceitação de filhos LGBTI, onde são narradas histórias de pessoas cisgêneras que revelam que, "apesar de amar aquele ente", não conseguem estar junto por não suportarem tamanha violência, que a mera possibilidade daquilo que seus entes poderiam vivenciar Ihes causa.

Um corpo dissidente como o meu, que procura romper com a condição de alguém que não aceita mais se calar, procurando deixar o lugar subalterno para me constituir como pessoa pensante e crítica das minhas ações, faz-se ato político. [...] meu lugar de enunciação foi sempre dominado por outros que nos classificaram como anormais, nos assujeitaram como alguém inferior, nos humilharam, nos transformaram em apenas um corpo a ser estudado ou simplesmente nos mataram. Os oprimidos podem e devem falar por si mesmos (buscando instrumentalizar-se para serem ouvidos). Eu, como mulher travesti, não permito que meu discurso seja invalidado ou menor. Sou uma pesquisadora do asfalto, da luta de viver a cada dia com a possibilidade de uma morte eminente (diante da letal ação do estado sobre alguns corpos) (GONÇALVES JR, 2018, p. 16).

\section{Programa: um ato manifesto ̧̦}

Ұ̛ Não falem de nossos nós, por nós e/ou sem nós!

\&̛ Jamais use o poder do conhecimento como arma e contra um corpo ou um grupo tão deslegitimado como o nosso, de travestis! Muitas escolhas são políticas e questioná-las é validarnos como menores ou incapazes de saber, decidir e conhecer a história. 
廿̛ Não hierarquizem nossas identidades (todas são formas de acesso às políticas públicas). Travestis, mulheres transgêneras e mulheres transexuais são identidades transvestigeneres que devem ser tratadas com igual respeito (sendo fixas em muitas existências perpetuadas ou devires em tantas outras).

廿 Não existe uma única forma de ser travesti. Temos diversas travestilidades e possibilidades de ser travesti. Nenhuma é igual a outra (o experimento da expressão de gênero pode ou não ser constitutivo); não generalize.

† Nossa transcestralidade importa (e se não soubermos de nossess/os/as antepassades/os/as, explique sem nos hierarquizar)!

ช̛ Representatividade importa se pressupor compromisso social, senso de coletividade, compromisso com a transfomação e ruptura das estruturas transfóbicas e de exclusão.

†े Nome social é uma política importante para travestis (que não querem ou não podem mudar de nome). Respeite nossa singularidade!

\& Reveja os aspectos gramaticais em sua fala/escrita e pense o quanto a língua portuguesa falada e/ou escrita contempla pessoas binárias masculinas. A língua é viva e como nossa cultura, ela também está mudando, transvestigenere-se! Inclua todes outres sujeites!

ซ̛ Travestis podem ter filhes/os/as (ou não) e constituir família (se desejarem).

†̛ Não quer ter uma filha travesti, não tenha filhos. As chances de ter uma filha trans é a mesma de ter um/a/e filho/a/e destro/a/e ou canhoto/a/e. Acolham as crianças trans e travestis, é nesse momento que mais precisamos de apoio.

† O gueto foi/é importante para nós. Ali aprendemos a nos ajudar e nos compreender como seres coletivos. Parem de ignorar ou sugerir que nossos "quilombos" não tiveram importância para a nossa sobrevivência.

Ұ̛ Sobrevivemos à epidemia do HIV. Somos filhas da AIDS. Netas da Violência. E hoje queremos mais (em terra Brazilis, quem perdoa é Jesus!), queremos reparação histórica, já!

†̛ Prostituição não é crime no Brasil, poderia ser uma opção para muitas de nós, mas numa sociedade justa não podemos suportar que qualquer pessoa esteja nesta profissão enquanto destino compulsório, inicial e final de sua existência.

ఫ̛ Viveremos e as nossas trans-epistemologias também! (com sua inconsciência ou isenção diante dos nossos temas e demandas).

ช̛ Contrate uma Travesti. Ajude em sua formação e qualificação. Pague por consultoria quando precisar de uma travesti para escrever sobre nós.

ఫ̛ Façam eventos, propagandas, filmes, peças ou qualquer coisa sobre nós, desde que haja travesti(s) participando efetivamente na equipe.

Ұ̛ Pesquisas: alimente a política da inserção, podemos escrever juntas/os/es/xs. Respeite o lugar de fala - fale a partir do que lhe toca e como lhe toca - isso significa ir além e (re)pensar (a sua pesquisa, seu objeto) seu olhar sobre a vida.

†̛ Não fetichizem nossos corpos. O país que mais acessa pornografia trans/travesti é o mesmo país que ainda discute casamento homoafetivo e enxerga trans/travestis como extensão de orientação sexual.

Ұ̛ Não somos violentas. Esse discurso alimenta os processos de exclusão das travestis dos espaços sociais, ainda que nossa "docilidade" fosse ensinada nas escolas, em nossas famílias e sociedade. Chega de "dar a outra face"!

†̛ O sorriso e o bom gosto sempre foram uma marca travesti de sobrevivência, mas estamos além das baladas, somos os sorrisos nas redes sociais, mas exigimos responsabilidade social com as causas que nos visibilizam. Vivemos antes, agora e no futuro, oportunizar um agora é construir um futuro possível e menos violento e, quem sabe, um dia de paz. 


\section{Referências}

AMARAL, Marília dos Santos; SILVA, Talita Caetano; CRUZ, Karla de Oliveira; TONELI, Maria Juracy Filgueiras. "'Do travestismo às travestilidades': uma revisão do discurso acadêmico no Brasil entre entre 2001-2010". Revista Psicologia \& Sociedade, v. 2, n. 26, p. 301-31 1, 2014.

ANDRADE, Luma Nogueira de. Travestis na escola: assujeitamento e resistência à ordem normativa. 2012. Tese (Doutorado em Educação) - Universidade Federal do Ceará, Fortaleza, 2012.

ANTRA. "Relatório Completo de Assassinatos de Travestis e Transexuais da Antra". Antra, 2019. Disponível em https://antrabrasil.org/assassinatos/.

ANZALDÚA, Gloria. "La conciencia de la mestiza / rumo a uma nova consciência". Revista Estudos Feministas, v. 13, n. 3, 2005. Disponível em https://www.scielo.br/scielo.php?script=sci_arttext\&pid= S0104-026X2005000300015.

BENTO Berenice M. A reinvenção do corpo: sexualidade e gênero na experiência transexual. 2003. Tese (Doutorado em Sociologia) - Departamento de Sociologia, Universidade de Brasília, Brasília, 2003.

BENTO Berenice M. "Brasil: o país do transfeminícidio". Revista Fórum, 2014. Disponível em https:// revistaforum.com.br/noticias/brasil-o-pais-transfeminicidio/. Acesso em 25/07/2020.

BORGES, Rosane. "Sobre imagens intoleráveis: o episódio Verônica Bolina". Instituto Geledés, 2015. Disponível em https://www.geledes.org.br/sobre-imagens-intoleraveis-o-episodio-veronica-bolina/. Acesso em 25/07/2020.

FOUCAULT, Michel. Microfísica do poder. Rio de Janeiro: Graal, 1979.

FOUCAULT, Michel. História da Sexualidade I. A vontade de saber. 13. ed. Rio de Janeiro: Graal, 1988.

FOUCAULT, Michel. O governo de si e dos outros. São Paulo: Wmf Martins Fontes, 2010.

GONÇALVES JR, Sara Wagner Pimenta. "As (Trans)Alianças e a Neomaquinaria". Carta Capital, 2019. Disponível em https://www.cartacapital.com.br/justica/as-transaliancas-e-a-neomaquinaria/ . Acesso em 27/07/2020.

GONÇALVES JR, Sara Wagner Pimenta. Corpos transgressores: Políticas de resistências. Campinas: Pontes, 2018.

HALBERSTAM, Jack. Gaga feminism. Estados Unidos: Beacon Press Books, 2012.

HARAWAY, Donna. "A manifesto for cyborgs: Science, technology, and socialist feminism in the 1980s". The postmodern turn: New perspectives on social theory, p. 82-115, 1994.

JUNQUEIRA, Rogério Diniz (Org.). Diversidade sexual na educação: problematizações sobre homofobia nas escolas. Brasília: Ministério da Educação, Secretaria de Educação Continuada, Alfabetização e Diversidade, UNESCO, 2009.

KILOMBA, Grada. Memórias da plantação: episódios de racismo cotidiano. Rio de Janeiro: Cobogá, 2019.

MARTINI, Paula; SABÓIA, Gabriel. "Pesquisadores trans ainda enfrentam desconfiança sobre sua produção acadêmica”. Rádio Globo, 2018. Disponível em https://cutt.ly/zhsy3M7.

MBEMBE, Achille. Necropolítica. São Paulo: N-1, 2019.

MIRANDA, Ana Maria. "Ex-atleta Caitlyn Jenner recebe prêmio por assumir que é trans". Uol, 16/07/ 2015. Disponível em https://cutt.ly/2hsyOn3.

OLIVEIRA, Megg Rayara Gomes de. "Transexistências negras: O lugar de travestis e mulheres transexuais negras no Brasil e em África até o século XIX". In: RIBEIRO, Paula Regina Costa et al. Corpo, gênero e sexualidade: resistência e ocupa(ações) nos espaços de educação. Rio Grande: EDFURG, 2018.

PELÚCIO, Larissa. Abjeção e desejo: uma etnografia travesti sobre o modelo preventivo de aids. São Paulo: FAPESP, 2009. 
PERES, William Siqueira. "Cenas de exclusões anunciadas: travestis, transexuais, transgêneros e a escola brasileira". In: JUNQUEIRA, Rogério Diniz (Org.). Diversidade sexual na educação: problematizações sobre a homofobia nas escolas. Brasília, DF: MEC/UNESCO, 2009. p. 235-263.

PRECIADO, Paul B. Manifesto Contrassexual. Tradução de Maria Paula Gurgel Ribeiro. São Paulo: N$1,2017$.

RODOVALHO, Amara Moira. "Cis pelo Trans". Revista Estudos Feministas, v. 25, n. 1, p. 365-373, 2017.

SANTOS, Dayana Carlin Brunetto dos. Cartografias da transexualidade: a experiência escolar e outras tramas. 2010. Dissertação (Mestrado em Educação) - Universidade Federal do Paraná, 2010.

SARNEY, José. "Presidenta ou presidente". Academia Brasileira, 2010. Disponível em https:// www.academia.org.br/artigos/presidenta-ou-presidente.

SPIVAK, Marla; GILLIAM, Martha. "Hygienic behaviour of honey bees and its application for control of brood diseases and Varroa: Part II. Studies on hygienic behaviour since the Rothenbuhler era". Bee world, v. 79, n. 4, p. 169-186, 1998.

STRYKER, Susan. Transgender History. Berkeley: Seal Press, 2008.

SUSSEKIND, Maria Luiza; YORK, Sara Wagner; CARMO, Lorena Azevedo do. "- Quem vai ao banheiro é o quê? - É gente”. Coletiva, 2020. Disponível em https://www.coletiva.org/educacao-e-diferencase-n12. Acesso em 28/06/2020.

VIEIRA, Fernanda Dantas. "A caça aos homossexuais e às travestis na ditadura militar". Pragmatismo Político, 2015. Disponível em https://cutt.ly/7hsy55d. Acesso em 08/08/2019.

Sara Wagner York/Sara Wagner Pimenta Gonçalves Jr. (sarayork.Iondon@yahoo.co.uk) é pai, travesti, pesquisadora e avó. Licenciada em Pedagogia (UERJ) e Letras - Inglês e respetivas Literaturas (UNESA), graduanda em Letras - Português e respectivas literaturas (UNESA) e mestre em Educação - GENI/ProPEd - UERJ. Foi bolsista CNPq.

Megg Rayara Gomes Oliveira (meggrayaragomes@gmail.com) é Professora Adjunta e Professora Credenciada no Programa de Pós-Graduação em Educação no Setor de Educação da Universidade Federal do Paraná; coordenadora do Núcleo de Estudos Afro-Brasileiros da Universidade Federal do Paraná. Pesquisa Gênero, Diversidade Sexual e Relações Étnico-Raciais.

Bruna Benevides (brunamarx@gmail.com) Marinha do Brasil, Sargenta da Marinha do Brasil, autora do Dossiê dos Assassinatos e da Violência contra Travestis e Transexuais Brasileiras, coordenadora do Pré-Vestibular Social - PreparaNem -, de Niterói-RJ, secretária de articulação política da Associação Nacional de Travestis e Transexuais (ANTRA), secretária de comunicação da Associação Brasileira de Lésbicas, Gays, Bissexuais, Travestis, Transexuais e Intersexos (ABGLT), membro da Rede Nacional de Operadores de Segurança Pública LGBTI+ (RENOSP LGBTI+) e membro fundadora do Fórum Estadual de Travestis e Transexuais do Rio de Janeiro (Fórum TTRJ). 
COMO CITAR ESSE ARTIGO DE ACORDO COM AS NORMAS DA REVISTA

YORK, Sara Wagner/GONÇALVES JUNIOR, Sara Wagner Pimenta; OLIVEIRA, Megg Rayara Gomes; BENEVIDES, Bruna. "Manifestações textuais (insubmissas) travesti". Revista Estudos Feministas, Florianópolis, v. 28, n. 3 , e75614, 2020.

\section{CONTRIBUIÇÃO DE AUTORIA}

As autoras contribuíram igualmente.

\section{FINANCIAMENTO}

Não se aplica.

CONSENTIMENTO DE USO DE IMAGEM

Não se aplica.

APROVAÇÃo DE COMITÊ DE ÉTICA EM PESQUISA

Não se aplica.

\section{CONFLITO DE INTERESSES}

Não se aplica.

LICENÇA DE USO

Este artigo está licenciado sob a Licença Creative Commons CC-BY Internacional. Com essa licença você pode compartilhar, adaptar, criar para qualquer fim, desde que atribua a autoria da obra.

\section{HISTÓRICO}

Recebido em 13/07/2020

Reapresentado em 29/07/2020

Aprovado em 17/08/2020

\section{Errata}

Neste artigo, na página 8

Onde se lia:

3 Programa: um ato manifesto

Leia-se:

4 Programa: um ato manifesto

Nas referências

Onde se lia:

JUNQUEIRA, Rogério Diniz; JESUS, Danie Marcelo de; MELO, Glenda Cristina Valin de; TCHALIAN, Vicente. "Homofobia nas escolas: um problema de todos". In: JUNQUEIRA, Rogério Diniz (Org.). Diversidade sexual na educação: problematizações sobre homofobia nas escolas. Brasília: Ministério da Educação, Secretaria de Educação Continuada, Alfabetização e Diversidade, UNESCO, 2009.

Leia-se:

JUNQUEIRA, Rogério Diniz (Org.). Diversidade sexual na educação: problematizações sobre homofobia nas escolas. Brasília: Ministério da Educação, Secretaria de Educação Continuada, Alfabetização e Diversidade, UNESCO, 2009. 